\title{
Short-Video Apps as a Health Information Source for Chronic Obstructive Pulmonary Disease: Information Quality Assessment of TikTok Videos
}

Shijie Song ${ }^{1}, \mathrm{PhD}$; Xiang Xue ${ }^{2}$, MSc; Yuxiang Chris Zhao ${ }^{3}, \mathrm{PhD}$; Jinhao $\mathrm{Li}^{4}$, BSc; Qinghua $\mathrm{Zhu}^{2}$, PhD; Mingming Zhao ${ }^{5}$, MD

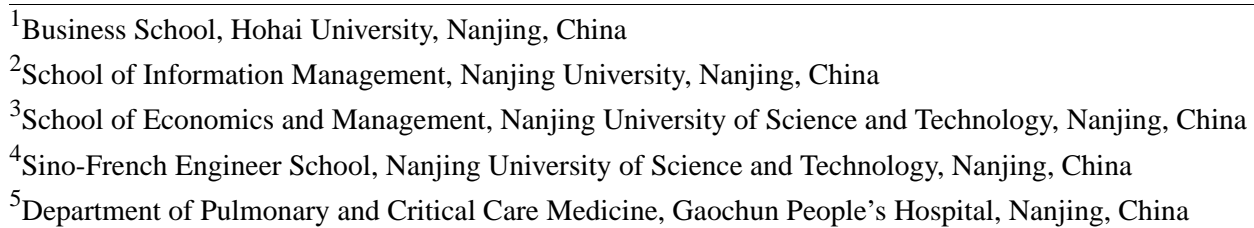

Corresponding Author:

Mingming Zhao, MD

Department of Pulmonary and Critical Care Medicine

Gaochun People's Hospital

Maoshan Rd 53

Economic Development Area, Gaochun District

Nanjing, 211300

China

Phone: 8615951973800

Email: mingtze80@163.com

\section{Abstract}

Background: Chronic obstructive pulmonary disease (COPD) has become one of the most critical public health problems worldwide. Because many COPD patients are using video-based social media to search for health information, there is an urgent need to assess the information quality of COPD videos on social media. Recently, the short-video app TikTok has demonstrated huge potential in disseminating health information and there are currently many COPD videos available on TikTok; however, the information quality of these videos remains unknown.

Objective: The aim of this study was to investigate the information quality of COPD videos on TikTok.

Methods: In December 2020, we retrieved and screened 300 videos from TikTok and collected a sample of 199 COPD-related videos in Chinese for data extraction. We extracted the basic video information, coded the content, and identified the video sources. Two independent raters assessed the information quality of each video using the DISCERN instrument.

Results: COPD videos on TikTok came mainly from two types of sources: individual users ( $\mathrm{n}=168$ ) and organizational users $(n=31)$. The individual users included health professionals, individual science communicators, and general TikTok users, whereas the organizational users consisted of for-profit organizations, nonprofit organizations, and news agencies. For the 199 videos, the mean scores of the DISCERN items ranged from 3.42 to 4.46 , with a total mean score of 3.75. Publication reliability $(P=.04)$ and overall quality $(P=.02)$ showed significant differences across the six types of sources, whereas the quality of treatment choices showed only a marginally significant difference $(P=.053)$ across the different sources.

Conclusions: The overall information quality of COPD videos on TikTok is satisfactory, although the quality varies across different sources and according to specific quality dimensions. Patients should be selective and cautious when watching COPD videos on TikTok.

(J Med Internet Res 2021;23(12):e28318) doi: 10.2196/28318

\section{KEYWORDS}

COPD; information quality; social media; short-video apps; TikTok 


\section{Introduction}

Chronic obstructive pulmonary disease (COPD) has become one of the most critical public health problems, which has resulted in huge health care expenditures [1]. In 2015, COPD caused approximately 3.17 million deaths worldwide, which accounted for $5 \%$ of global deaths for that year [2]. COPD is notably more severe in low- and middle-income countries than in high-income countries. From 2014 to 2015, approximately $5.9 \%$ of adults in the United States were reported to be living with COPD [3], whereas the estimated prevalence was $13.6 \%$ in China during the same period [4].

COPD is a preventable and treatable disease, and there are many opportunities to reduce the risk of COPD before and after diagnosis $[5,6]$. For example, general health consumers could reduce the risk of contracting COPD by quitting smoking and avoiding secondhand smoke [7]. Even after a COPD diagnosis, maintaining a healthy lifestyle can help patients prevent exacerbations and improve well-being [8]. However, limited access to information about COPD has become a significant problem for patients and their caregivers [9]. People living with COPD often report limited knowledge on several points such as the causes of COPD and its consequences [10]. Patients have also often received inadequate guidance about how to recognize the disease, and avoid and manage exacerbations [10,11]. Therefore, effective health communications that inform patients on recommended actions are important for better disease prevention and management, and information communication technologies can play a substantial role in such communication and intervention [12].

Emerging technologies provide great health communication opportunities that can inform and empower COPD patients in regard to disease management [13]. For example, mobile technologies have been extensively used to help COPD patients achieve an early diagnosis [14], make medical appointments [15], promote physical activity [16], consistently self-monitor [17], enhance self-management [18], and reduce COPD exacerbation [12]. Recently, visually rich social media (eg, YouTube, Pinterest) have become popular among COPD patients $[19,20]$. In general, rich social media have several advantages in health communication. The information can be illustrated, which makes it easier to process and remember than information in the form of plain text [21]. Imagistic health information can elicit affective reactions and motivate consumers' health actions [22]. Some prior studies suggest that COPD patients exposed to visually rich social media are more willing to engage with COPD-related messages [19,23].

Despite the promising potential of any emerging technology, patients' actual use of a technology can be fraught with problems. Some evidence suggests that information quality is one of the most significant concerns when COPD patients seek health information online [24]. Evaluating the quality of online health information sources is not an easy task for most laypeople $[25,26]$, especially for many COPD patients who have low health literacy [27]. According to a survey of COPD patients, approximately half of the respondents reported difficulty distinguishing between high- and low-quality health resources on the internet [27]. Therefore, health care providers should assess the information quality of online COPD information and advise their patients about it.

To the best of our knowledge, the quality of online COPD information in video-based social media has yet to be sufficiently investigated. Stellefson et al [20] reviewed 223 videos employing the instruments of HONcode (Health on the Net) principles; they found that the majority of YouTube COPD videos $(69.1 \%)$ were of high quality and were mainly created by authoritative sources (eg, health agencies, organizations, news agents, and professionals). Recently, the short-video app TikTok has attracted significant research attention in regard to its health communication. For example, during the COVID-19 pandemic, TikTok's coronavirus-related videos were viewed 93.1 billion times as of July 2020 [28]. The originality, interactivity, and sociable nature of TikTok have given the younger generation a better user experience and sense of engagement while seeking health information [29]. TikTok affords rich information modalities (eg, text, image, audio, and video), and contains ample technology features such as commenting, chatting, following, liking, and live-streaming [30]. These features make the app easier for the general public to use as a source of health information, and penetration and usage of TikTok are also on the rise among some older age groups [31].

We observed that there are many COPD-related videos on TikTok. However, the quality of the information they offer remains unclear. Therefore, to fill this gap, the aim of this study was to evaluate the information quality of COPD videos on TikTok.

\section{Methods}

\section{Search Strategy and Data Extraction}

We employed three Chinese words, “慢性阻塞性肺疾病” (chronic obstructive pulmonary disease), “慢性阻塞性肺病” (chronic lung disease related to obstructed airflow), and “慢阻 肺” (COPD), to retrieve the relevant COPD videos on TikTok. In its search function, TikTok provides three ways to sort items: "overall ranking," "most recent," and "most likes." Overall ranking is the default mode of sorting recommended by TikTok, which also comprises the other two modes. Given that most users employ the default, we used the overall ranking mode to retrieve the top 100 videos posted from December 6 to December 10, 2020, under each of the three keywords, which resulted in a total of 300 videos. We chose the threshold number of 100 for two reasons. First, TikTok's search function encompasses the consideration of topic relevance; the pertinent COPD videos mostly appear at the top of the result list, and it is hard to observe any relevant videos when the results go beyond 100. Second, most general health consumers apply the "least effort" principle in their online information-seeking activities; thus, they usually view the top search results instead of going very far [32].

To choose the most relevant videos, we removed videos that were (1) duplicates $(n=72),(2)$ not directly related to COPD 
topics $(n=17)$, and (3) advertisements $(n=12)$. Finally, a total of 199 videos remained for data analysis (see Figure 1).

We used Microsoft Excel to extract and code the basic information from each video. This included a description of the video; the URL; the upload date; the duration (in seconds); the user ID of the uploader; and the numbers of views, likes, and comments.

Figure 1. Search strategy and video screening procedure.

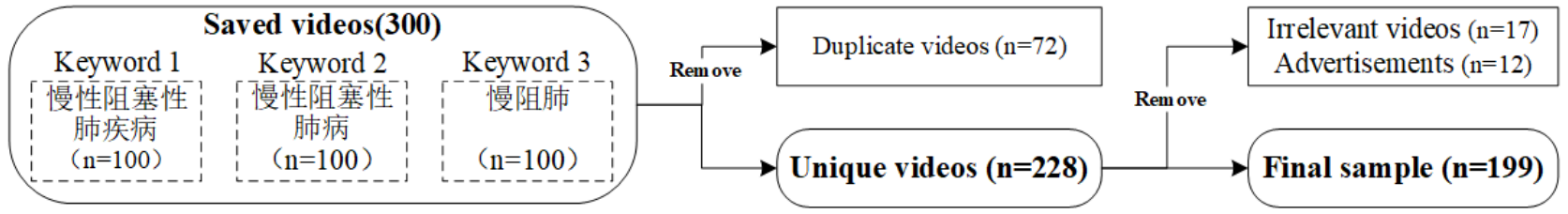

\section{Instruments}

We employed DISCERN as the instrument for assessing the quality of the information in each video. DISCERN is a brief questionnaire designed to help health consumers and researchers assess the quality of health information. The questionnaire contains three parts, devoted to the reliability of a publication (8 items), the quality of information on treatment choices (7 items), and an overall rating of the publication (1 item) [33]. Each of the 16 questions is rated on a scale of 1 (lowest score) to 5 (highest score). We chose DISCERN for several reasons: (1) it is one of the most widely used instruments for studying the quality of health information [34], (2) it has proven to be effective in Chinese contexts [35], and (3) it has proven to be useful for assessing information quality on other video-based platforms (eg, YouTube) [36]. The full instrument is presented in Multimedia Appendix 1.

Moreover, we adopted six questions from Goobie et al [37] to evaluate the video content. These six questions ask to what degree a video addresses the definition of a disease, its signs and symptoms, risk factors, evaluation, management, and outcomes. Each aspect was scored on a three-item scale: not addressed ( 0 points), partially addressed (1 point), and sufficiently addressed ( 2 points).

\section{Coding Procedure}

Two raters (MZ and YZ) independently evaluated the information quality of each video, employing the DISCERN instrument. Both raters are certified physicians who worked in a local hospital in the division of respiratory disease. The coding procedure contained three stages.

In the first stage, we recorded the basic information of the video publishers (eg, account name, self-description, identity verification status) and the basic information of the videos (eg, publication date, video length, number of likes, number of comments, number of shares). Regarding the video publishers, we categorized the video sources into two main types (ie, individual users and organizational users) by their account names and identity verification status. Further, we identified several subcategories within each source type by their account names, self-description, and video publication records. For example, if a video publisher described themselves as a "scientific writer," we would code the source as an "individual science communicator."

In the second stage, we assessed the video content using the six categories from Goobie et al [37]: the definition of a disease, its signs and symptoms, risk factors, evaluation, management, and outcomes. When we had independently scored the first 30 videos, we found that we were able to reach a consensus on whether a video contains a certain category of content. One rater (MZ) then finished rating the rest of the videos and the other rater (YZ) validated the codes, followed by discussion and resolution of any inconsistencies between the two raters.

In the third stage, we evaluated the information quality by applying the DISCERN instrument. Before starting to score the videos, the two raters first reviewed the official DISCERN scoring instructions, discussing how the tool could be operationalized for evaluating video-based content and making necessary adjustments. Using the DISCERN questions, the two raters scored all videos independently. The overall rating agreement (Cohen $\kappa)$ was $0.793(P<.001)$, which indicated that the rating process had satisfactory interrater reliability. Any between-group analyses regarding DISCERN scores were performed using the Kruskal-Wallis H test in SPSS 22.

\section{Results}

\section{Video Characteristics}

The COPD videos on TikTok came mainly from two types of sources: individual users and organizational users. Most of the COPD TikTok videos in our sample were contributed by individual users $(168 / 199,84.4 \%)$, whereas a relatively small share was contributed by organizational users $(31 / 199,15.6 \%)$. For each type, we identified three subcategories (see Table 1). Among individual users, health professionals created the most videos, followed by individual science communicators and general TikTok users. Among organizational users, for-profit organizations published the highest number of videos, followed by nonprofit organizations and news agencies.

In the sample, the durations of the videos varied from 10 to 4116 seconds. The videos published by nonprofit organizations were significantly longer than videos from other sources, whereas the videos published by news agencies had the shortest average duration. Videos published by individual science communicators had the second-longest average duration. The average duration for the other sources was under 1 minute (Table 2).

The most recent video was published 22 days prior to data collection, whereas the oldest had been on TikTok for more than 1 year. The 199 videos received a total of 1,696,725 likes and 175,703 comments prior to data collection. The number of 
likes varied from 0 to 662,000 for each video, and the number of comments ranged from 0 to 18,000 . The videos published by health professionals received the most likes and comments, whereas the videos uploaded by individual science communicators received the least likes and comments. Since their publication, the videos in the overall sample had been shared a total of 167,473 times. The videos uploaded by health professionals were shared the most frequently, whereas the videos created by individual science communicators were shared the least frequently, as shown in Table 2.

Table 1. Characteristics of the sources of chronic obstructive pulmonary disease-related TikTok videos $(\mathrm{N}=199)$.

\begin{tabular}{lll}
\hline Source & Description & Videos, $\mathrm{n}(\%)$ \\
\hline $\begin{array}{l}\text { Individual users } \\
\text { General users }\end{array}$ & Common TikTok users & $30(15.1)$ \\
$\quad$ Individual science communicators & $\begin{array}{l}\text { Individuals who participate in general scientific communications, } \\
\text { which may include but are not limited to health care domains }\end{array}$ & $39(19.6)$ \\
$\quad$ & Individuals who describe themselves as health professionals & $99(49.7)$ \\
Health professionals & & $18(9.0)$ \\
Organizational users & Private sector organizations & $8(4.0)$ \\
$\quad$ For-profit organizations & Organizations or hospitals operating in the public sector & $5(2.5)$ \\
$\quad$ Nonprofit organization & Organizations providing news services
\end{tabular}

Table 2. Characteristics of chronic obstructive pulmonary disease-related TikTok videos, by source

\begin{tabular}{|c|c|c|c|c|c|}
\hline Source of videos & $\begin{array}{l}\text { Days on TikTok, } \\
\text { median (IQR) }\end{array}$ & $\begin{array}{l}\text { Video duration (seconds), } \\
\text { median (IQR) }\end{array}$ & $\begin{array}{l}\text { Number of likes, medi- } \\
\text { an (IQR) }\end{array}$ & $\begin{array}{l}\text { Number of } \\
\text { comments, me- } \\
\text { dian (IQR) }\end{array}$ & $\begin{array}{l}\text { Number of shares, } \\
\text { median (IQR) }\end{array}$ \\
\hline \multicolumn{6}{|l|}{ Organizational users } \\
\hline For-profit organizations & $180(39-297)$ & $59(37-129)$ & $364(115-4915)$ & $17(7-32)$ & $19(7-133)$ \\
\hline Nonprofit organizations & $148(44-225)$ & $158(74-206)$ & $24(14-40)$ & $1(0-2)$ & $1(0-8)$ \\
\hline News agencies & $145(22-147)$ & $34(18-51)$ & $12(1-18)$ & $0(0-0)$ & $3(1-3)$ \\
\hline \multicolumn{6}{|l|}{ Individual users } \\
\hline Health professionals & $407(144-490)$ & $57(49-59)$ & $1031(170-3203)$ & $54(8-161)$ & $58(12-334)$ \\
\hline $\begin{array}{l}\text { Individual science communi- } \\
\text { cators }\end{array}$ & $303(147-491)$ & $85(45-116)$ & $3(1-11)$ & $0(0-1)$ & $0(0-5)$ \\
\hline General users & $237(133-394)$ & $40(15-59)$ & $19(9-49)$ & $2(1-5)$ & $1(0-7)$ \\
\hline Overall & $276(119-478)$ & $57(43-88)$ & $125(12-1597)$ & $7(1-91)$ & $12(1-118)$ \\
\hline
\end{tabular}

\section{Information Quality}

The videos covered the six predefined content areas to different degrees, as shown in Figure 2. The results suggested that more than half of the videos $(122 / 199,61.3 \%)$ sufficiently addressed COPD outcomes, whereas only $16(8.0 \%)$ made no mention of outcomes. The second most frequently introduced area concerned the signs or symptoms of COPD, with almost half of the videos $(100 / 199,50.3 \%)$ sufficiently addressing them and $76(38.2 \%)$ only giving partial mentions. Moreover, approximately half of the videos only partially mentioned the topics of COPD evaluation, management, and risk factors. The least frequently mentioned topic was the definition of COPD; only 25 videos $(12.6 \%)$ sufficiently addressed this and 47 videos $(23.6 \%)$ did not mention it at all.

We calculated the mean scores for each DISCERN item for the total sample. The scores ranged from 3.42 to 4.46 (mean 3.75). The scores of the eight items measuring publication reliability (items 1-8) varied from 3.42 to 4.46 (mean 3.90). For the seven items assessing the quality of information on treatment choices (items 9-15), the scores ranged from 3.45 to 3.69 (mean 3.56). The remaining item (item 16) measuring overall information quality achieved a mean of 3.85 out of 5 points. We categorized the DISCERN items into three sections according to the original instrument indicated: reliability of the publication, quality of information on treatment choices, and overall rating of the publication (see Table 3).

Videos published by nonprofit organizations had the highest reliability, whereas the videos contributed by general users had the lowest reliability. The differences in publication reliability across the six types of video sources were statistically significant. Regarding the quality of information on treatment choices, the nonprofit organizations provided the highest-quality videos, whereas the general users provided the lowest-quality videos; however, the differences among the various information sources were only marginally significant. With regard to the last item concerning overall rating, the highest-quality videos were created by news agencies and the lowest-quality videos 
were generated by for-profit organizations. The overall rating of information quality showed significant differences according to different sources. Overall, the total scores of the entire
DISCERN questionnaire across the different sources exhibited significant differences (Table 3).

Figure 2. Percentage of videos addressing each chronic obstructive pulmonary disease topic.

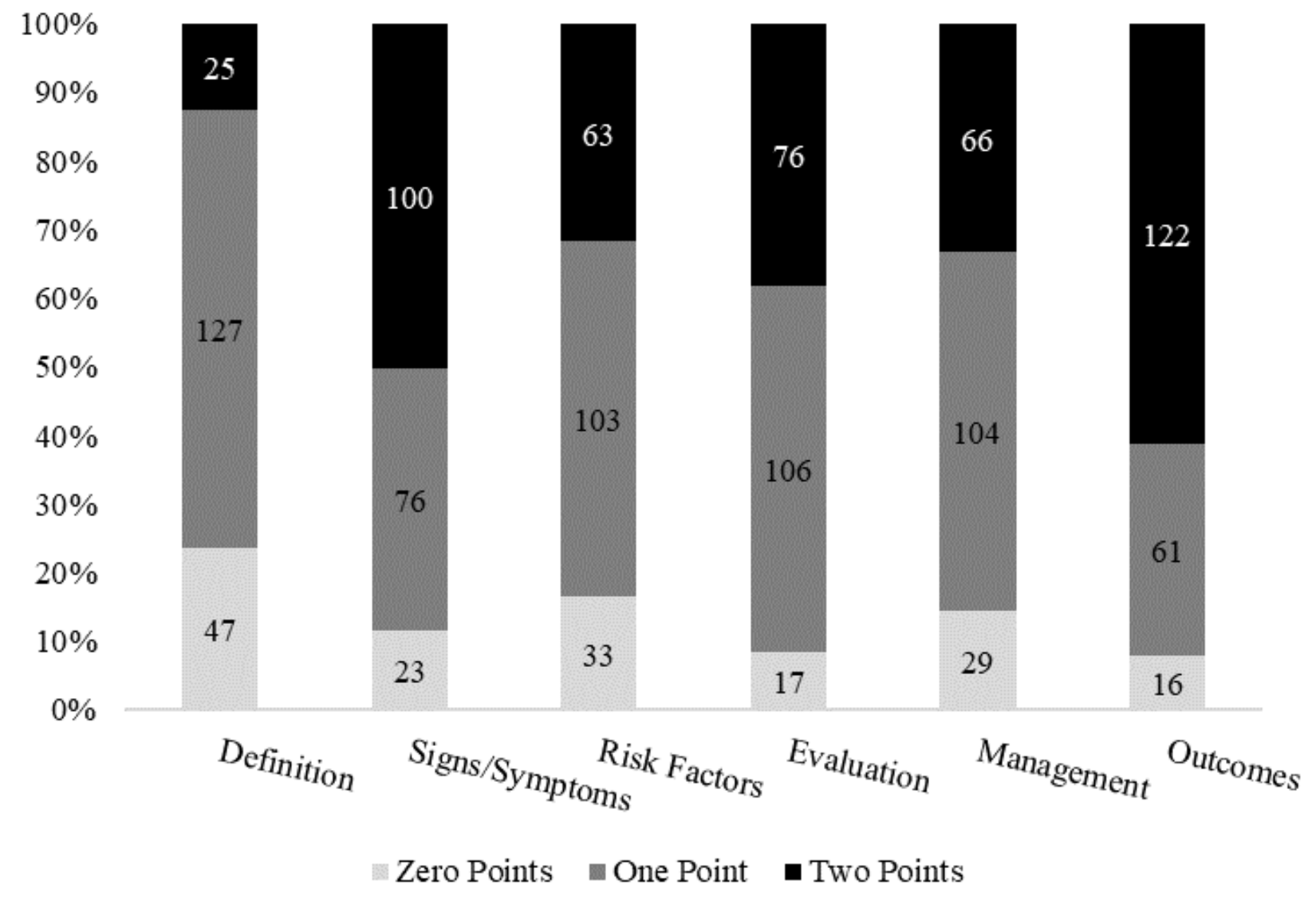

Table 3. DISCERN scores of chronic obstructive pulmonary disease-related TikTok videos by source $(\mathrm{N}=199)$.

\begin{tabular}{|c|c|c|c|c|c|c|c|}
\hline Category & $\begin{array}{l}\text { For-profit organiza- } \\
\text { tions }(\mathrm{n}=18)\end{array}$ & $\begin{array}{l}\text { Nonprofit or- } \\
\text { ganizations } \\
(n=8)\end{array}$ & $\begin{array}{l}\text { News agen- } \\
\text { cies }(n=5)\end{array}$ & $\begin{array}{l}\text { Health professionals } \\
(\mathrm{n}=99)\end{array}$ & $\begin{array}{l}\text { Science communica- } \\
\text { tors }(\mathrm{n}=39)\end{array}$ & $\begin{array}{l}\text { General users } \\
(\mathrm{n}=30)\end{array}$ & $P$ value ${ }^{\mathrm{a}}$ \\
\hline \multicolumn{7}{|c|}{ Publication reliability } & .04 \\
\hline Median & 30.5 & 34.5 & 34 & 32 & 33 & 30 & \\
\hline Mean (SD) & $29.8(5.9)$ & $34.5(1.31)$ & $34.1(1.4)$ & $31.1(3.7)$ & $31.1(4.4)$ & $29.7(5.8)$ & \\
\hline Treatment choices & & & & & & & .053 \\
\hline Median & 24.3 & 28 & 26 & 25.5 & 26 & 23 & \\
\hline Mean (SD) & $22.8(5.7)$ & $28.1(2.93)$ & $27.3(3.9)$ & $25.3(4.2)$ & $25(4.5)$ & $23.1(6.1)$ & \\
\hline Overall quality & & & & & & & .02 \\
\hline Median & 4 & 4 & 4 & 4 & 4 & 4 & \\
\hline Mean (SD) & $3.4(0.9)$ & $4.2(0.65)$ & $4.4(0.5)$ & $3.8(0.6)$ & $3.9(0.7)$ & $3.6(0.9)$ & \\
\hline Total score & & & & & & & .01 \\
\hline Median & 60 & 67 & 66 & 61 & 62 & 57 & \\
\hline Mean (SD) & $56(11.8)$ & $66.8(3.8)$ & $65.8(4.5)$ & $60.4(7.3)$ & $60(8.9)$ & $56.5(11.1)$ & \\
\hline
\end{tabular}

${ }^{\mathrm{a}} P$ values were calculated with the Kruskal-Wallis $\mathrm{H}$ test. 


\section{Discussion}

\section{TikTok as a Health Information Source}

Recently, video-based social media platforms and apps have been gaining popularity among patients with chronic conditions [38]. For example, YouTube has become a prominent platform for generating and spreading health-related videos, covering topics related to chronic disease management, including disease prevention, diagnosis, and treatment [39]. Although some recent evidence indicates that TikTok has had vast communication potential during the COVID-19 pandemic [40], the role of TikTok in disseminating chronic disease information remains unclear.

Our results suggest that TikTok could be a promising channel for disseminating COPD information. The 199 videos surveyed in our study have received approximately 1.7 million likes and 176,000 comments since they were published. Given that most of the videos were published within 1 year, the numbers of likes and comments are relatively high. Therefore, we suggest that health care professionals and institutions leverage short-video apps (eg, TikTok) to improve patient education and health communication.

\section{Information Quality}

To the best of our knowledge, the quality of online information about COPD is understudied. Specifically in regard to short-video apps, the information quality of COPD videos remains unclear. As one of the earliest studies to tackle this problem, this study yielded results suggesting that the general information quality of COPD videos on TikTok is relatively satisfactory. Although there is a concern that TikTok may differentiate itself from other social media by targeting quirky videos rather than serious professional content [30], our results indicate that the quality of health information found on TikTok, particularly that related to COPD, is acceptable. These results are consistent with a recent survey of coronavirus-related videos on TikTok, which found that the information provided in these videos was generally credible, containing merely $4.3 \%$ misinformation [41].

Our findings show that the COPD videos on TikTok more or less touched on all of the preidentified COPD-related content. More than half of the videos sufficiently described the outcomes and the signs and symptoms, and partially addressed the topics of evaluation, risk factors, and management. However, few videos offered definitions of COPD. A possible explanation for this is that TikTok videos are created for a target audience of laypeople. Therefore, introducing aspects of disease management is more important than discussing academic definitions of COPD.

\section{Sources of COPD-Related Videos on TikTok}

This study reveals that both individual users and organizational users are engaged in creating COPD videos on TikTok. We identified three specific subcategories for each of these two general categories of sources (ie, individual users and organizational users). Individual users included health professionals, general TikTok users, and individual science communicators. We found that many health professionals were active in communicating COPD knowledge; they contributed almost half of the videos in our sample. Organizational communicators of health information included nonprofit organizations, for-profit organizations, and news agencies. Recently, some researchers have suggested that video-based social media such as TikTok are playing increasingly important roles in providing general health information sought or encountered by consumers [40,41]; therefore, health experts and traditional institutions should harness and leverage social media platforms and apps to better disseminate health information and medical knowledge to the public $[41,42]$. In general, the findings of this study indicate that health professionals and reputable organizations are actively engaged in communicating health information on TikTok.

In addition, the results suggest that the information quality of COPD videos on TikTok varies according to the source. The videos published by nonprofit organizations had the highest average score for the reliability of publications, while the videos created by general TikTok users had the lowest average score; the differences were statistically significant. The nonprofit organizations and general TikTok users earned the highest and lowest average scores for the quality of information on treatment choices, respectively, although the differences were only marginally significant. For the overall rating of information quality, the news agencies contributed content of significantly higher quality than that of other sources. All of these results are consistent with prior studies in YouTube settings, where organizational users were found to create videos of significantly higher quality than those of individual users [20,37].

Communication performance varied among the sources. In our sample, the videos published by health professionals received the most likes and comments, and were most frequently shared by users. The videos created by individual science communicators received the least likes and comments and were least likely to be shared by users. Interestingly, despite the significant differences in communication performance, we found that the two sources had comparable levels of objective information quality, as assessed by the DISCERN instrument. Prior information credibility studies suggest that credibility depends on the perception of the information recipient, which may not necessarily reflect the objective quality of the information $[25,43]$, and users' credibility perception predicts whether or not they will adopt and share health information on social media [44]. The discrepancy between information quality and communication performance may partially confirm such findings. We suspect that health professionals convey a higher level of expertise and thus generate greater credibility, whereas general science communicators convey low expertise in medicine when they upload videos with wide topic coverage extending beyond the medical domain. We call for future research to investigate the discrepancies between the actual quality of health information and users' credibility perception.

\section{Limitations and Future Research}

This study has some limitations. First, we employed only the DISCERN instrument, which was chosen because it has worked well in prior studies that assessed the quality of information in health-related videos. However, there are other instruments 
available, such as the JAMA (Journal of the American Medical Association) benchmarks and the HONcode, and future research could expand these investigations by using different instruments. Second, this study only assessed the information quality of Chinese COPD videos. Although the locality did not impact the overall results, the conclusions may not necessarily be generalizable to COPD videos in other languages; therefore, we call for more cross-language comparative studies in the future.

\section{Conclusion}

This study investigated the information quality of COPD videos on the world's largest short-video app, TikTok, employing the
DISCERN instrument. The results show that both organizational and individual users generate COPD-related content. The overall information quality of the COPD-related videos in the sample was satisfactory, although the quality varied across the different video sources and specific quality dimensions. The results suggest that patients should remain cautious and selective when watching COPD videos on TikTok. Videos from identifiable sources (eg, nonprofit organizations) are much more strongly recommended than those from other nonverified sources. Based on the limitations of this study, we have proposed several directions for future research.

\section{Acknowledgments}

We thank Dr Ya Zhang for her contribution to the data analysis and the anonymous reviewers and editors for their helpful comments on the manuscript. The study is supported by the National Science Foundation of China (grant numbers 72174083, 72074112, and 71774083) and the Postgraduate Research \& Practice Innovation Program of Jiangsu Province (grant number KYCX19_0022).

\section{Conflicts of Interest}

None declared.

\section{Multimedia Appendix 1}

The DISCERN questionnaire.

[DOCX File, 13 KB-Multimedia Appendix 1]

\section{References}

1. Quaderi S, Hurst J. The unmet global burden of COPD. Glob Health Epidemiol Genom 2018;3:e4 [FREE Full text] [doi: 10.1017/gheg.2018.1] [Medline: 29868229]

2. Chronic obstructive pulmonary disease (COPD). World Health Organization. URL: https://www.who.int/news-room/ fact-sheets/detail/chronic-obstructive-pulmonary-disease-(copd) [accessed 2020-12-29]

3. Sullivan J, Pravosud V, Mannino DM, Siegel K, Choate R, Sullivan T. National and state estimates of COPD morbidity and mortality - United States, 2014-2015. Chronic Obstr Pulm Dis 2018 Oct 12;5(4):324-333. [doi: 10.15326/jcopdf.5.4.2018.0157] [Medline: 30723788]

4. Fang L, Gao P, Bao H, Tang X, Wang B, Feng Y, et al. Chronic obstructive pulmonary disease in China: a nationwide prevalence study. Lancet Respir Med 2018 Jun;6(6):421-430 [FREE Full text] [doi: 10.1016/S2213-2600(18)30103-6] [Medline: 29650407]

5. Li P, Lu X, Teng C, Cai P, Kranis M, Dai Q, et al. The impact of COPD on in-hospital outcomes in patients with Takotsubo cardiomyopathy. Int J Chron Obstruct Pulmon Dis 2020;15:2333-2341. [doi: 10.2147/COPD.S267289] [Medline: 33061351]

6. Li P, Dai Q, Cai P, Teng C, Pan S, Dixon RA, et al. Identifying different phenotypes in takotsubo cardiomyopathy by latent class analysis. ESC Heart Fail 2021 Feb;8(1):555-565. [doi: 10.1002/ehf2.13117] [Medline: 33244882]

7. Zhao Q, Meng M, Kumar R, Wu Y, Huang J, Lian N, et al. The impact of COPD and smoking history on the severity of COVID-19: A systemic review and meta-analysis. J Med Virol 2020 Oct;92(10):1915-1921 [FREE Full text] [doi: 10.1002/jmv.25889] [Medline: $\underline{\text { 32293753] }}$

8. de Blok BMJ, de Greef MHG, ten Hacken NHT, Sprenger SR, Postema K, Wempe JB. The effects of a lifestyle physical activity counseling program with feedback of a pedometer during pulmonary rehabilitation in patients with COPD: a pilot study. Patient Educ Couns 2006 Apr;61(1):48-55. [doi: 10.1016/j.pec.2005.02.005] [Medline: 16455222]

9. Nakken N, Janssen DJA, van den Bogaart EHA, Muris JWM, Vercoulen JH, Custers FL, et al. Knowledge gaps in patients with COPD and their proxies. BMC Pulm Med 2017 Oct 30;17(1):136 [FREE Full text] [doi: 10.1186/s12890-017-0481-8] [Medline: 29084521]

10. Hernandez P, Balter M, Bourbeau J, Hodder R. Living with chronic obstructive pulmonary disease: a survey of patients' knowledge and attitudes. Respir Med 2009 Jul;103(7):1004-1012 [FREE Full text] [doi: 10.1016/j.rmed.2009.01.018] [Medline: 19269150]

11. Stellefson M, Paige SR, Alber JM, Chaney BH, Chaney D, Apperson A, et al. Association between health literacy, electronic health literacy, disease-specific knowledge, and health-related quality of life among adults with chronic obstructive pulmonary 
disease: cross-sectional study. J Med Internet Res 2019 Jun 06;21(6):e12165 [FREE Full text] [doi: 10.2196/12165] [Medline: 31172962]

12. Alwashmi M, Hawboldt J, Davis E, Marra C, Gamble J, Abu Ashour W. The effect of smartphone interventions on patients with chronic obstructive pulmonary disease exacerbations: a systematic review and meta-analysis. JMIR Mhealth Uhealth 2016 Sep 01;4(3):e105 [FREE Full text] [doi: 10.2196/mhealth.5921] [Medline: 27589898]

13. Han X, Li B, Zhang T, Qu J. Factors associated with the actual behavior and intention of rating physicians on physician rating websites: cross-sectional study. J Med Internet Res 2020 Jun 04;22(6):e14417 [FREE Full text] [doi: 10.2196/14417] [Medline: 32496198]

14. De Ramón Fernández A, Ruiz Fernández D, Marcos-Jorquera D, Gilart Iglesias V. Support system for early diagnosis of chronic obstructive pulmonary disease based on the service-oriented architecture paradigm and business process management strategy: development and usability survey among patients and health care providers. J Med Internet Res 2020 Mar 17;22(3):e17161 [FREE Full text] [doi: 10.2196/17161] [Medline: 32181744]

15. Jiang Y, Liu F, Guo J, Sun P, Chen Z, Li J, et al. Evaluating an intervention program using WeChat for patients with chronic obstructive pulmonary disease: randomized controlled trial. J Med Internet Res 2020 Apr 21;22(4):e17089 [FREE Full text] [doi: 10.2196/17089] [Medline: 32314971]

16. Bentley CL, Powell L, Potter S, Parker J, Mountain GA, Bartlett YK, et al. The use of a smartphone app and an activity tracker to promote physical activity in the management of chronic obstructive pulmonary disease: randomized controlled feasibility study. JMIR Mhealth Uhealth 2020 Jun 03;8(6):e16203 [FREE Full text] [doi: 10.2196/16203] [Medline: 32490838]

17. Stamenova V, Liang K, Yang R, Engel K, van Lieshout F, Lalingo E, et al. Technology-enabled self-management of chronic obstructive pulmonary disease with or without asynchronous remote monitoring: randomized controlled trial. J Med Internet Res 2020 Jul 30;22(7):e18598 [FREE Full text] [doi: 10.2196/18598] [Medline: 32729843]

18. Korpershoek YJG, Hermsen S, Schoonhoven L, Schuurmans MJ, Trappenburg JCA. User-centered design of a mobile health intervention to enhance exacerbation-related self-management in patients with chronic obstructive pulmonary disease (Copilot): mixed methods study. J Med Internet Res 2020 Jun 15;22(6):e15449 [FREE Full text] [doi: 10.2196/15449] [Medline: $\underline{\text { 32538793] }}$

19. Paige SR, Stellefson M, Chaney BH, Alber JM. Pinterest as a resource for health information on chronic obstructive pulmonary disease (COPD): a social media content analysis. Am J Health Educ 2015 Jul 06;46(4):241-251. [doi: $\underline{10.1080 / 19325037.2015 .1044586]}$

20. Stellefson M, Chaney B, Ochipa K, Chaney D, Haider Z, Hanik B, et al. YouTube as a source of chronic obstructive pulmonary disease patient education: a social media content analysis. Chron Respir Dis 2014 May;11(2):61-71 [FREE Full text] [doi: 10.1177/1479972314525058] [Medline: 24659212]

21. Rus HM, Cameron LD. Health communication in social media: message features predicting user engagement on diabetes-related Facebook pages. Ann Behav Med 2016 Oct;50(5):678-689. [doi: 10.1007/s12160-016-9793-9] [Medline: 27059761]

22. Feng B, Malloch Y, Kravitz R, Verba S, Iosif A, Slavik G, et al. Assessing the effectiveness of a narrative-based patient education video for promoting opioid tapering. Patient Educ Couns 2021 Feb;104(2):329-336. [doi: 10.1016/j.pec.2020.08.019] [Medline: $\underline{32900605]}$

23. Paige SR, Stellefson M, Chaney BH, Chaney DJ, Alber JM, Chappell C, et al. Examining the relationship between online social capital and eHealth literacy: implications for Instagram use for chronic disease prevention among college students. Am J Health Educ 2017;48(4):264-277 [FREE Full text] [doi: 10.1080/19325037.2017.1316693] [Medline: 29152031]

24. Paige SR, Stellefson M, Krieger JL, Alber JM. Computer-mediated experiences of patients with chronic obstructive pulmonary disease. Am J Health Educ 2019;50(2):127-134 [FREE Full text] [doi: 10.1080/19325037.2019.1571963] [Medline: 31641399]

25. Song S, Zhang Y, Yu B. Interventions to support consumer evaluation of online health information credibility: A scoping review. Int J Med Inform 2021 Jan;145:104321. [doi: 10.1016/j.ijmedinf.2020.104321] [Medline: 33202372]

26. Sun Y, Zhang Y, Gwizdka J, Trace CB. Consumer evaluation of the quality of online health information: systematic literature review of relevant criteria and indicators. J Med Internet Res 2019 May 02;21(5):e12522 [FREE Full text] [doi: 10.2196/12522] [Medline: 31045507$]$

27. Stellefson ML, Shuster JJ, Chaney BH, Paige SR, Alber JM, Chaney JD, et al. Web-based health information seeking and eHealth literacy among patients living with chronic obstructive pulmonary disease (COPD). Health Commun 2018 Dec;33(12):1410-1424 [FREE Full text] [doi: 10.1080/10410236.2017.1353868] [Medline: 28872905]

28. Ostrovsky AM, Chen JR. TikTok and its role in COVID-19 information propagation. J Adolesc Health 2020 Nov;67(5):730 [FREE Full text] [doi: 10.1016/j.jadohealth.2020.07.039] [Medline: 32873499]

29. Song S, Zhao YC, Yao X, Ba Z, Zhu Q. Short video apps as a health information source: an investigation of affordances, user experience and users' intention to continue the use of TikTok. Internet Res 2021 Jun 24;31(6):2120-2142. [doi: 10.1108/intr-10-2020-0593]

30. Wang Y. Humor and camera view on mobile short-form video apps influence user experience and technology-adoption intent, an example of TikTok (DouYin). Comput Hum Behav 2020 Sep;110:106373. [doi: 10.1016/j.chb.2020.106373] 
31. Nakamura A. TikTok Teens Follow New Stars: Senior Citizens. The Wall Street Journal. 2020. URL: https://www.wsj.com/ articles/tiktok-teens-follow-new-stars-senior-citizens-11605724082 [accessed 2021-05-17]

32. Case D, Given L. Looking for information: a survey of research on information seeking, needs, and behavior. UK: Emerald Group Publishing; 2016.

33. Charnock D, Shepperd S, Needham G, Gann R. DISCERN: an instrument for judging the quality of written consumer health information on treatment choices. J Epidemiol Community Health 1999 Feb;53(2):105-111 [FREE Full text] [doi: 10.1136/jech.53.2.105] [Medline: 10396471]

34. Zhang Y, Sun Y, Xie B. Quality of health information for consumers on the web: a systematic review of indicators, criteria, tools, and evaluation results. J Assn Inf Sci Tec 2015 Apr 29;66(10):2071-2084. [doi: 10.1002/asi.23311]

35. Sun F, Yang F, Zheng S. Evaluation of the liver disease information in Baidu Encyclopedia and Wikipedia: longitudinal study. J Med Internet Res 2021 Jan 18;23(1):e17680 [FREE Full text] [doi: 10.2196/17680] [Medline: 33459597]

36. Aydin M, Aydin M. Quality and reliability of information available on YouTube and Google pertaining gastroesophageal reflux disease. Int J Med Inform 2020 May;137:104107. [doi: 10.1016/j.ijmedinf.2020.104107] [Medline: 32146372]

37. Goobie GC, Guler SA, Johannson KA, Fisher JH, Ryerson CJ. YouTube videos as a source of misinformation on idiopathic pulmonary fibrosis. Annals ATS 2019 May;16(5):572-579. [doi: 10.1513/annalsats.201809-644oc]

38. Kong W, Song S, Zhao YC, Zhu Q, Sha L. TikTok as a health information source: assessment of the quality of information in diabetes-related videos. J Med Internet Res 2021 Sep 01;23(9):e30409 [FREE Full text] [doi: 10.2196/30409] [Medline: $\underline{34468327]}$

39. Madathil KC, Rivera-Rodriguez AJ, Greenstein JS, Gramopadhye AK. Healthcare information on YouTube: A systematic review. Health Informatics J 2015 Sep;21(3):173-194 [FREE Full text] [doi: 10.1177/1460458213512220] [Medline: 24670899]

40. Comp G, Dyer S, Gottlieb M. Is TikTok the next social media frontier for medicine? AEM Educ Train 2021 Jul;5(3):10.1002/aet2.10532 [FREE Full text] [doi: 10.1002/aet2.10532] [Medline: 34095694]

41. Basch C, Hillyer G, Jaime C. COVID-19 on TikTok: harnessing an emerging social media platform to convey important public health messages. Int J Adolesc Med Health 2020 Aug 10:online ahead of print. [doi: 10.1515/ijamh-2020-0111] [Medline: $\underline{32776899]}$

42. Song S, Zhao YC, Yao X, Ba Z, Zhu Q. Serious information in hedonic social applications: affordances, self-determination and health information adoption in TikTok. J Document 2021 Nov 19;ahead-of-print. [doi: 10.1108/JD-08-2021-0158]

43. Zhang Y, Song S. Older adults' evaluation of the credibility of online health information. 2020 Presented at: Conference on Human Information Interaction and Retrieval; March 14-18, 2020; Vancouver, BC p. 358-362. [doi: $10.1145 / 3343413.3377997]$

44. Luo C, Luo X, Schatzberg L, Sia CL. Impact of informational factors on online recommendation credibility: The moderating role of source credibility. Decision Support Syst 2013 Dec;56:92-102. [doi: 10.1016/j.dss.2013.05.005]

\author{
Abbreviations \\ COPD: chronic obstructive pulmonary disease \\ HON: Health on the Net \\ JAMA: Journal of the American Medical Association
}

Edited by G Eysenbach; submitted 05.03.21; peer-reviewed by P Li, P Zou, L Spencer; comments to author 10.05.21; revised version
received 23.05.21; accepted 18.11.21; published 20.12.21
Please cite as:
Song $S$, Xue X, Zhao YC, Li J, Zhu Q, Zhao M
Short-Video Apps as a Health Information Source for Chronic Obstructive Pulmonary Disease: Information Quality Assessment of
TikTok Videos
J Med Internet Res $2021 ; 23(12): e 28318$
URL: https://www.jmir.org/2021/12/e28318
doi: $\underline{10.2196 / 28318}$
PMID:

(CShijie Song, Xiang Xue, Yuxiang Chris Zhao, Jinhao Li, Qinghua Zhu, Mingming Zhao. Originally published in the Journal of Medical Internet Research (https://www.jmir.org), 20.12.2021. This is an open-access article distributed under the terms of the Creative Commons Attribution License (https://creativecommons.org/licenses/by/4.0/), which permits unrestricted use, distribution, and reproduction in any medium, provided the original work, first published in the Journal of Medical Internet 
Research, is properly cited. The complete bibliographic information, a link to the original publication on https://www.jmir.org/, as well as this copyright and license information must be included. 